\title{
PENGOLAHAN GONDORUKEM MENJADI BAHAN PENDARIHAN SEBAGAI ADITIF PADA PEMBUATAN KERTAS
}

\author{
Mahammad Khadafi ${ }^{1}$, Ike Rostika, Taufan Hidayat \\ Balai Besar Pulp dan Kertas, Jl. Raya Dayeuhkolot No. 132 Bandung \\ ${ }^{1}$ mahammadkhadafi@gmail.com \\ Diterima : 06 Maret 2014, Revisi akhir : 16 Mei 2014, Disetujui terbit : 30 Mei 2014 \\ GONDORUKEM PROCESSING TO BE SIZING AGENT FOR \\ ADDITIVE SUBSTANCE IN PAPERMAKING
}

\begin{abstract}
Gondorukem (Resina colophium) is produced by steam distillation of pine resin (oleoresin). It is yellow-brown solid containing mainly tricyclic alkyl organic acids (abietat acid and pimarate acid). The two acids have ampliphilic characteristics due to their hydrophobic carboxyl tail and hydrophilic tricyclic molecules. The purpose of this research was to prepare emulsion rosin as a sizing agent. Two types of gondorukem ( $W W$ and $X$ grades) were saponified by adding a sodium hydroxide solution at a temperature below $100 \mathrm{oC}$. For improving the quality of saponified rosins, the rosins were fortified by adding some maleic anhydride. Some tests were conducted to measure saponified and acidic numbers of a known rosin grade. The tests show that the acidic and saponified numbers of an $X$ grade rosin were 179.92 and 199.74, respectively. Those of a $W W$ grade were 176.58 and 195.84 for acidic and saponified numbers, respectively. Therefore, it can be concluded that the X grade gondorukem has a better quality as a rosin sizing agent than the $W W$ grade.
\end{abstract}

Keywords: gondorukem, saponification, sizing agent, fortified rosin

\begin{abstract}
ABSTRAK
Gondorukem (Resina colophium) adalah hasil olahan destilasi uap dari getah sadapan pada batang pinus (oleoresin). Gondorukem berbentuk padatan berwarna kuning kecoklatan dengan komponen kimia utamanya terdiri dari asam organik alkyl tricyclic tak jenuh yaitu asam abietat dan asam pimarat. Kedua molekul asam ini memiliki sifat amfipatik yaitu mempunyai gugus karboksil yang bersifat hidrofilik dan molekul tricyclic yang hidrofobik. Penelitian ini bertujuan untuk pembuatan darih rosin emulsi dari gondorukem serbuk sebagai aditif pada pembuatan kertas. Gondorukem dengan kualitas WW dan X dilakukan reaksi saponifikasi menggunakan soda pada suhu di bawah $100^{\circ} \mathrm{C}$. Peningkatan kualitas dari rosin tersabunkan yang terbentuk dilakukan dengan reaksi fortifikasi menjadi rosin terfortifikasi dengan penambahan senyawa anhidrida maleat. Parameter uji berupa bilangan penyabunan dan bilangan asam dilakukan untuk mengetahui kualitas darih rosin yang terbentuk. Dari penelitian ini didapatkan bilangan asam dan penyabunan kualitas X adalah 179,92 dan 199,74 sedangkan untuk kualitas WW 176,58 dan 195,84. Dengan hasil pengujian kualitas bahan baku gondorukem X mempunyai kualitas yang lebih baik untuk dijadikan darih rosin pada kertas dibandingkan dengan WW.
\end{abstract}

Kata kunci: gondorukem, saponifikasi, bahan pendarihan, rosin terfortifikasi 


\section{PENDAHULUAN}

Gondorukem (Resina colophium) adalah hasil olahan destilasi uap getah sadapan batang pinus (oleoresin) selain minyak terpentin. Gondorukem berbentuk padatan berwarna kuning kecoklatan, sedangkan minyak terpentin berwujud cairan putih bening. Rosin atau gondorukem merupakan asam organik alkyl tricyclic tak jenuh yang berasal dari derivat alam. Komponen senyawa utama dari rosin adalah asam abietat dan asam pimarat yang memiliki sifat amfipatik yaitu mempunyai gugus karboksil yang bersifat hidrofilik dan molekul tricyclic yang bersifat hidrofobik (Wiyono, 2009).

Indonesia sebagai produsen gondorukem ke-3 terbesar di dunia dengan volume produksi mencapai 60.000 ton/tahun, harus dapat memanfaatkan gondorukem sebagai bahan baku menjadi produk yang mempunyai nilai tambah agar nilai jual ekspor dari produk gondorukem menjadi lebih meningkat (Fachrodji, 2010). Potensi penggunaan dari senyawa gondorukem diantaranya banyak dimanfaatkan untuk bahan industri kertas, bahan pelunak plester, sebagai campuran perona mata (eyeshadow), batik, sabun, vernis, isolasi alat listrik dan tinta cetak. Gondorukem digunakan pula sebagai bahan perekat yang berfungsi sebagai tackifier, pemacu perekatan (adhesion promoter) atau pemacu kekentalan (viscosity promoters) untuk memperbaiki sifat-sifat produk akhir (Coppen dkk., 1995).

Dalam industri kertas, gondorukem atau rosin digunakan sebagai bahan pendarihan (sizing agent) untuk memperbaiki sifat kertas. Rosin adalah bahan pendarih kertas alami yang bekerja pada kondisi $\mathrm{pH}$ asam. Selain itu, terdapat senyawa AKD (Alkil Keton Dimer) dan ASA (Alkenil Susksinat Anhidrida) yang merupakan bahan pendarih sintetik bekerja pada pH basa. Bahan pendarih (sizing agent) pada kertas berfungsi untuk memberikan daya tahan lembaran kertas terhadap sebaran dan penetrasi dari air (Boer dan Ella, 2001). Pendarihan dengan menggunakan bahan darih rosin merupakan proses pendarihan konvensional yang masih banyak digunakan hingga sekarang. Hal ini disebabkan sistem pendarihan konvensional memiliki keistimewaan tersendiri, diantaranya adalah karena bahan darih rosin dapat diperoleh dengan mudah dan relatif murah, serta prosesnya sederhana dengan hasil pendarihan yang cukup baik (Casey, 1981). Efektivitas pendarihan rosin sangat tergantung pada jumlah bahan darih rosin yang teretensi dalam lembaran kertas. Mekanisme retensi bahan darih rosin terjadi melalui ikatan antar muatan.

Proses pendarihan dengan menggunakan bahan rosin masih digunakan pada pembuatan kertas jenis asam. Namun, pendarihan dengan menggunakan rosin memiliki beberapa kelemahan diantaranya menurunkan permanensi lembaran, efluen yang dihasilkan banyak mengandung polutan, sifat fisik dari lembaran yang rendah dan menimbulkan sifat korosif pada mesin. Oleh karena itu, diperlukan suatu modifikasi dari rosin agar dapat bekerja pada $\mathrm{pH}$ netral ataupun basa. Salah satu metodenya yaitu menggunakan bahan pengendap (fixing agent) seperti polialumunium klorida (PAC) atau alumunium sulfat (alum) serta memodifikasi bentuk sediaan dari rosin itu sendiri menjadi rosin terfortifikasi atau rosin emulsi bermuatan (Wiyono dkk., 2008).

Dengan melihat potensi dari kegunaan gondorukem yang luas dan dapat digunakan sebagai bahan tambahan (aditif) untuk memperbaiki sifat kertas telah dilakukan penelitian pengolahan bahan baku gondorukem menjadi darih rosin emulsi untuk memberikan nilai tambah dari bahan baku gondorukem dan hasilnya dipaparkan dalam makalah ini.

\section{BAHAN DAN METODE}

\section{Bahan}

Bahan yang digunakan dalam penelitian adalah gondorukem kualitas WW dan gondorukem kualitas X yang berasal dari PGT Sindang Wangi Jawa Barat, etanol absolut, anhidrida maleat, formalin, larutan $\mathrm{HCl} 0,5 \mathrm{~N}$ dan $0,1 \mathrm{~N}$, larutan $\mathrm{KOH}$-alkohol 0,5 N dan 0,1 N. HCl pekat, larutan toluen, asam oksalat, natrium tetraboraks, $\mathrm{NaOH}$, dan air suling.

\section{Alat}

Alat yang digunakan dalam kegiatan penelitian ini adalah alat uji titik leleh gondorukem, tabung kondensor, Erlenmeyer, ekstraktor, alat titrimerti, gelas ukur, aluminium foil, termometer, labu leher 
tiga, water bath, magnetik stirer, gelas piala, pipet volume 10 dan $25 \mathrm{ml}$, labu takar $100 \mathrm{ml}$, pemangas listrik, termometer, dan alat pengujian sifat fisik kertas serta alat uji Cobb untuk daya serap air.

\section{METODE}

\section{Pengujian Sifat Fisik dan Kimia Gondorukem}

Pengujian sifat fisik gondorukem dilakukan meliputi pengujian warna, pengujian titik lunak berdasarkan SNI 7636 : 2011, pengujian kelarutan dalam toluen 1:1, pengujian kadar air berdasarkan SNI 08-7070-2005, pengujian bilangan asam berdasarkan RSNI3 7636 : 2010, pengujian rosin bebas berdasarkan TAPPI T 628 cm-01, pengujian kadar kotoran berdasarkan SNI $7636: 2011$.

\section{Pembuatan Darih Rosin Emulsi}

Darih rosin dapat dibuat dengan menambahkan basa-alkoholik terhadap gondorukem serbuk secara langsung. Pembuatan sabun rosin dari getah bersih sebagai berikut $219 \mathrm{~kg}$ getah bersih yang mengandung $65 \%$ rosin dengan $87 \%$ asam resin ditambah $34,2 \%$ terpentin, dan $1,8 \%$ air. Untuk menetralkan getah bersih ini ditambahkan $12,05 \mathrm{~kg} \mathrm{NaOH}$ yang dilarutkan dalam air sebanyak 23,75 kg air. Sehingga didapatkan perbandingan berat antara getah pinus: $\mathrm{NaOH}$ : air yaitu $18,7: 1: 1,97$. Sedangkan perbandingan mol antara getah dan larutan $\mathrm{NaOH}$ yaitu 0,26 mol : 0,11 mol (Summers dan Hendrik, 1962).

Gondorukem dalam bentuk padat digerus hingga menjadi serbuk untuk memperluas permukaan. Gondorukem bubuk diuji bilangan asam dan bilangan penyabunan sesuai dengan prinsip standar pada metode pengujian sifat fisik gondorukem. Hasil perhitungan dari pengujian tersebut untuk menghitung kebutuhan $\mathrm{NaOH}$ sesuai dengan teori Sammers dan Hendrik (1962). Kebutuhan $\mathrm{NaOH}$ yang didapatkan digunakan untuk proses saponifikasi serbuk gondorukem dengan menggunakan media reaksi $\mathrm{NaOH}$ - alkoholik untuk membentuk rosin saponifikasi. Rosin yang telah tersabunkan dibuat reaksi fortifikasi dengan penambahan asam lemak anhidrida maleat. Hal ini dimaksudkan untuk membentuk rosin fortifikasi. Rosin hasil fortifikasi selanjutnya diuji kelarutannya dengan menggunakan air dengan tujuan untuk mengetahui apakah rosin yang dibuat dapat larut dalam air. Proses pembuatan rosin emulsi dapat dilihat pada Gambar 1.

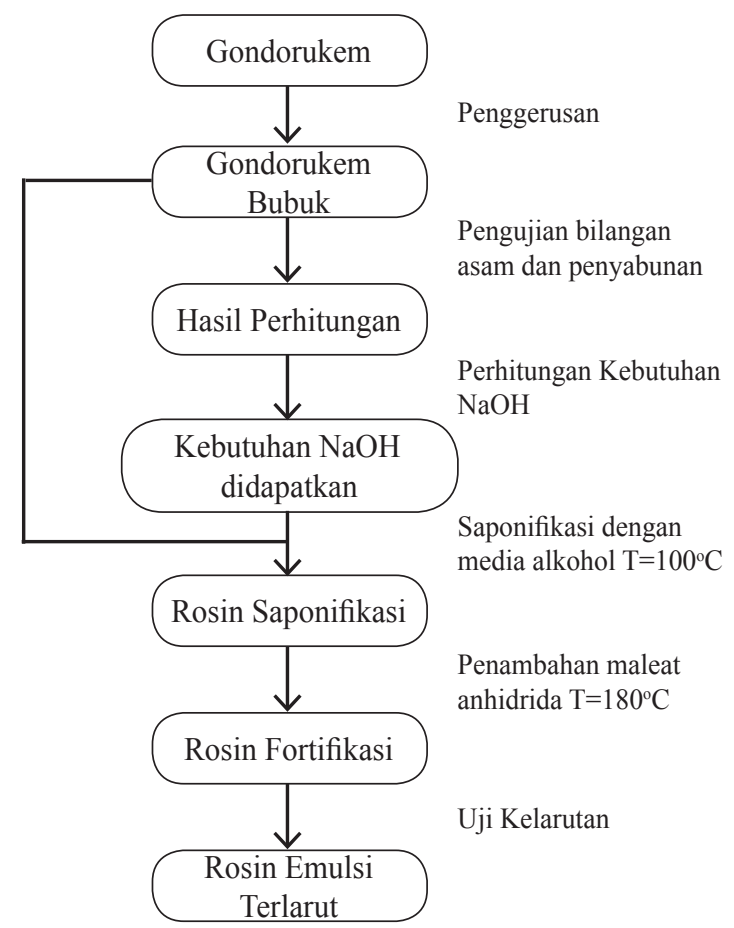

Gambar 1. Proses Pembuatan Rosin Emulsi

\section{HASIL DAN PEMBAHASAN}

\section{Pengujian Sifat Fisik dan Kimia}

Gondorukem yang digunakan sebagai bahan baku memiliki 2 kualitas yang berbeda yaitu kualitas X dan kualitas WW. Kedua jenis tipe ini dibandingkan mana yang paling sesuai dengan spesifikasi bahan baku untuk dibuat menjadi rosin emulsi. Pengujian sifat fisik dan kimia dari gondorukem telah dilakukan dengan cara melihat karakteristik 2 jenis gondorukem untuk kualitas X dan WW. Untuk kedua jenis kualitas gondorukem ini dilakukan pengujian sifat fisik yaitu berupa uji warna dan uji titik lunak. Sedangkan untuk uji kimia dilakukan pengujian bilangan asam, bilangan penyabunan, kadar kotoran dan kelarutan dalam toluen 1:1.Hasil dari pengujian sifat fisik dan kimia dapat dilihat pada Tabel 1.

Pada uji warna gondorukem untuk kualitas $\mathrm{X}$ dan WW (Gambar 2), kedua tipe gondorukem ini memiliki warna yang berbeda dimana kualitas WW memiliki warna kuning yang lebih pucat daripada kualitas X. Salah satu kriteria yang mempengaruhi kualitas gondorukem untuk digunakan pada berbagai macam aplikasi di 
industri adalah warna. Warna pada gondorukem menandakan daya oksidasi senyawa kimia terutama asam lemak terhadap reaksi dengan udara luar. Kualitas (grade) gondorukem secara umum dapat diketahui dari uji warna, apabila warna pada gondorukem semakin gelap (pucat) kualitas semakin baik. Hal ini karena dari warna dapat diduga tingkat kesempurnaan pengolahan gondorukem dari getah pinus, kerapuhan dan sifat-sifat lainnya yang terdapat dalam gondorukem (Siregar, 2002).

Tabel 1. Hasil Pengujian Sifat Fisik dan Kimia Gondorukem

\begin{tabular}{lcc}
\hline \multirow{2}{*}{ Pengujian } & \multicolumn{2}{c}{ Gondorukem } \\
\cline { 2 - 3 } & Kualitas X & $\begin{array}{c}\text { Kualitas } \\
\text { WW }\end{array}$ \\
\hline Warna & $\begin{array}{c}\text { Kuning } \\
\text { jernih }\end{array}$ & $\begin{array}{c}\text { Kuning } \\
\text { pucat }\end{array}$ \\
Bilangan asam & 179,92 & 176,58 \\
Bilangan penyabunan & 199,74 & 195,84 \\
Titik lunak & $88^{\circ} \mathrm{C}$ & $90^{\circ} \mathrm{C}$ \\
Kadar kotoran & $0,04 \%$ & $0,07 \%$ \\
Kelarutan dalam & Larut & Larut \\
toluene 1:1 & &
\end{tabular}

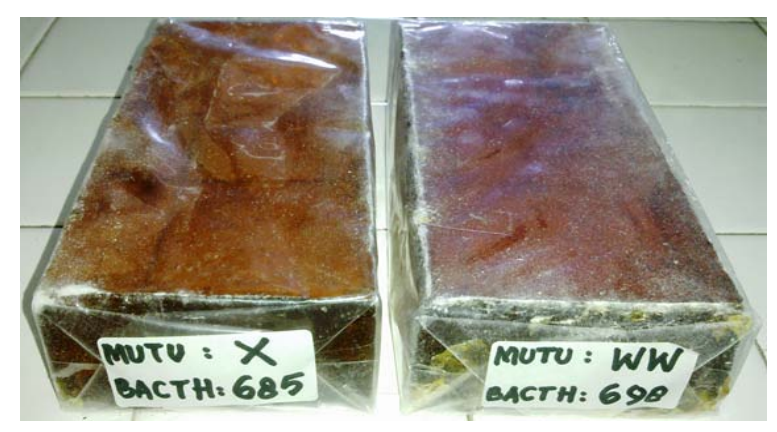

Gambar 2. Uji Warna Gondorukem dengan Membedakan Wujud Fisik Gondorukem

Titik lunak menunjukkan salah satu sifat khas gondorukem dan tingkat kemasakannnya. Tingkat kemasakan ini berhubungan erat dengan kadar terpentin tersisa dalam gondorukem, dimana makin kecil kadar terpentin tersisa maka makin tinggi titik lunak gondorukem (Djatmiko, dkk 1973). Dari hasil pengujian didapatkan gondorukem kualitas WW mempunyai titik lunak yang lebih tinggi yaitu $90^{\circ} \mathrm{C}$ pada tekanan normal. Untuk kualitas $\mathrm{X}$ didapatkan titik lunak dari gondorukem yaitu $88^{\circ} \mathrm{C}$. Dari hasil ini dapat dilihat bahwa gondorukem kualitas WW mempunyai kandungan pengotor yang lebih sedikit dibandingkan dengan kualitas $\mathrm{X}$. Kandungan pengotor pada gondorukem ini biasanya berupa terpentin ataupun senyawa organik asam lemak rantai pendek.

Bilangan asam adalah banyaknya kalium hidroksida $(\mathrm{KOH})$ dalam miligram yang diperlukan untuk menetralkan satu gram asam resin yang terkandung dalam senyawa gondorukem (RSNI3 7636 : 2010). Selain itu bilangan asam ditentukan untuk mengetahui jumlah asam lemak bebas yang terkandung dalam bahan dan dipergunakan untuk mengetahui tingkat kerusakan bahan yang disebabkan adanya proses hidrolisis. Hasil yang didapat menunjukkan bahwa gondorukem kualitas WW memiliki nilai bilangan asam 176,58 sedangan gondorukem kualitas $\mathrm{X}$ memiliki nilai bilangan asam 179,92. Hal ini menunjukkan bahwa gondorukem kualitas WW memiliki kandungan asam lemak yang lebih sedikit dibandingkan dengan gondorukem kualitas $\mathrm{X}$. Jika nilai bilangan asam dari bahan baku gondorukem telah diketahui maka kandungan asam lemak yang terdapat pada gondorukem dapat ditentukan. Kandungan asam lemak ini dapat digunakan sebagai perhitungan jumlah mol dari gondorukem yang akan dilakukan saponifikasi menggunakan basa dengan jumlah yang tepat.

Angka penyabunan menunjukkan berat molekul lemak dan minyak secara kasar. Minyak yang tersusun dari komponen kimia asam lemak berantai karbon pendek mempunyai berat molekul yang relatif kecil akan mempunyai angka penyabunan yang besar. Sebaliknya bila berat molekulnya besar, maka angka penyabunan relatif kecil (Harris, 1953). Dari hasil yang didapatkan pada analisa bahan baku gondorukem untuk kualitas $\mathrm{X}$ dan WW didapatkan nilai bilangan penyabunan 199,74 untuk kualitas X dan 195,84 untuk kualitas WW. Hasil ini menunjukkan bahwa gondorukem untuk kualitas $\mathrm{X}$ memiliki nilai bilangan penyabunan yang lebih tinggi sehingga kandungan asam lemak pada gondorukem kualitas $\mathrm{X}$ relatif rendah. Begitu pula untuk gondorukem kualitas WW dengan angka bilangan penyabunan yang lebih rendah sehingga kandungan asam lemak untuk kualitas WW lebih banyak. Bilangan penyabunan ini dapat digunakan sebagai pedoman awal dalam menentukan berapa banyak basa $\mathrm{NaOH} / \mathrm{KOH}$ 
yang digunakan untuk melarutkan senyawa asam abietat pada gondorukem.

Kelarutan adalah kemampuan suatu zat terlarut untuk larut dalam suatu pelarut. Kelarutan suatu senyawa bergantung pada sifat fisik dan kimia zat terlarut dan pelarut. Senyawa asam lemak abietat yang merupakan kandungan utama gondorukem umumnya larut dalam toluen dengan perbandingan 1:1. Hal ini disebabkan toluen adalah hidrokarbon aromatik yang banyak digunakan dalam industri sebagai pelarut (Harris, 1953).

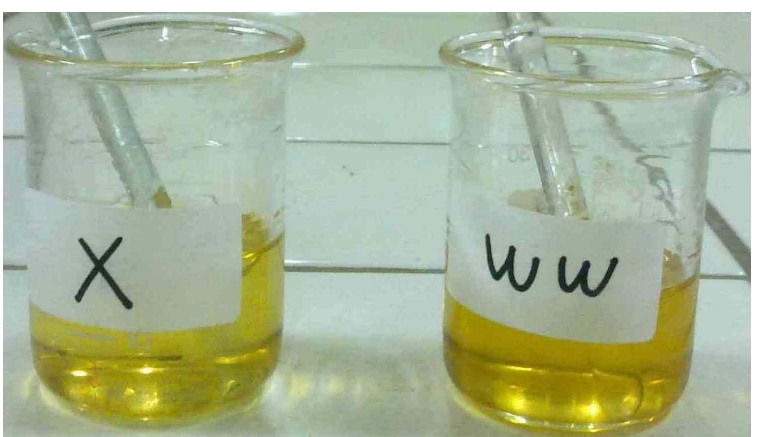

\section{Gambar 3. Uji Kelarutan Gondorukem dalam} Toluen $1: 1$

Uji kelarutan gondorukem kualitas $\mathrm{X}$ dan WW (Gambar 3) menunjukkan bahwa keduanya larut dalam toluen. Hal ini menandakan bahwa kedua kualitas gondoukem tersebut mempunyai kadar pengotor yang sangat sedikit, sehingga keduanya dapat larut dengan sempurna dalam pelarut organik toluen. Hal ini dapat disebabkan karena toluen adalah salah satu jenis pelarut yang bersifat non polar sehingga dapat melarutkan zat yang terdapat dalam gondorukem. Kirk dan Othmer (2007) menyatakan bahwa gondorukem dapat larut pada hampir semua pelarut organik seperti etilalkohol, etil eter, benzena dan pelarut non polar seperti toluen. Selain itu, dengan dibantu pengadukan akan mempercepat pelarutan bahan padat (gondorukem) tersebut. Namun jika dibandingakan dengan pelarut alkohol (etanol), kelarutan gondorukem dalam alkohol (etanol) ternyata menghasilkan kelarutan yang lebih cepat larut sempurna dibandingkan dengan toluen (Kirk dan Othmer, 2007).

Kadar kotoran adalah banyaknya bahan yang tidak larut dalam toluen yang dinyatakan dalam persen (SNI 7636: 2011). Gondorukem yang dikehendaki untuk berbagai macam industri adalah gondorukem yang bebas dari kotoran. Makin kecil kadar kotoran gondorukem maka makin jernih produk gondorukem yang dihasilkan dan akan semakin bagus kualitasnya untuk aplikasi di berbagai macam produk tertentu. Kualitas derivat gondorukem dapat dipengaruhi juga oleh kadar kotoran yang terkandung dalam gondorukem baik yang dapat dilihat maupun yang tidak terlihat oleh mata tanpa alat bantuan.Pada pengujian kadar kotoran gondorukem didapatkan bahwa kadar kotoran untuk kualitas WW 0,07\% lebih tinggi dibandingkan dengan gondorukem kualitas X $0,04 \%$. Kadar kotoran yang terdapat dalam gondorukem dapat diamati berupa nodanoda. Kotoran tersebut akan dapat terlihat jelas nantinya jika diterapkan dalam aplikasi produk tertentu, misalnya pada industri kertas. Dengan adanya kadar kotoran yang banyak dapat menyebabkan timbulnya noda - noda hitam pada kertas yang dihasilkan (Indriati dkk., 1993).

\section{Pembuatan Gondorukem Emulsi}

Proses pembuatan rosin emulsi dimulai dengan menghaluskan gondorukem menjadi serbuk untuk memperluas permukaan dan memudahkan dalam melakukan pelelehan gondorukem.

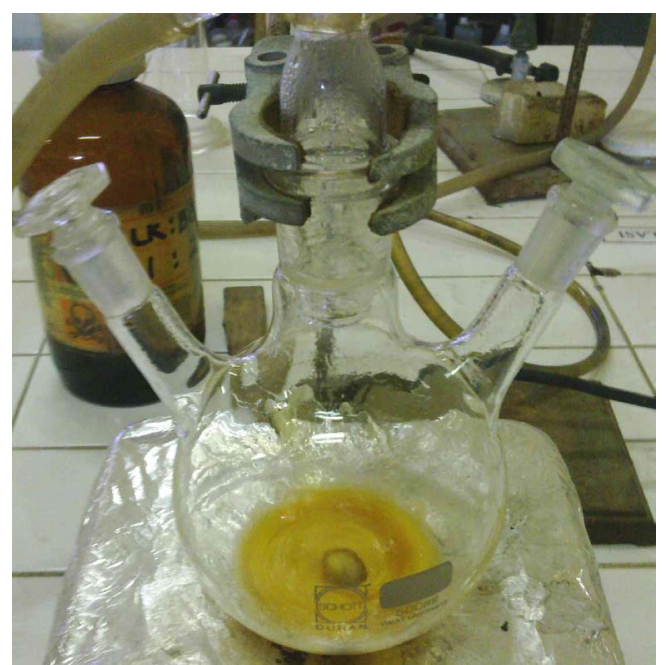

Gambar 4. Proses Pembuatan Rosin Emulsi dengan Metode Saponifikasi

Gondorukem yang telah menjadi serbuk tersebut lalu ditimbang sesuai dengan perbandingan hasil dari perhitungan bilangan penyabunan yang didapatkan. Perbandingan ini didasarkan pada perhitungan perbandingan mol antara asam lemak yang terkandung dalam gondorukem dengan basa $\mathrm{NaOH}$. Gambar 4 menunjukkan proses pembuatan rosin emulsi dengan metode saponifikasi. 
Gondorukem serbuk yang telah ditimbang dimasukkan ke dalam labu leher tiga bersamaan dengan serbuk anhidrida maleat. Penambahan serbuk anhidrida maleat dilakukan dengan variasi penambahan $0 \%, 3 \%, 5 \%$ dan $8 \%$. Kegunaannya yaitu untuk membentuk rosin fortifikasi agar senyawa rosin yang terbentuk lebih stabil. Selain itu juga penambahan asam anhidrida maleat dilakukan untuk meningkatkan derajat keasaman $(\mathrm{pH})$ dari rosin yang dilarutkan dengan saponifikasi. Kemudian serbuk gondorukem dan maleat anhidrida dipanaskan hingga meleleh pada suhu $180^{\circ} \mathrm{C}$ sambil diaduk dengan magnet agar tercampur dengan sempurna sehingga nantinya akan membentuk seperti karamel. Setelah itu dimulai proses saponifikasi dari gondorukem dengan menambahkan larutan $\mathrm{NaOH}$ alkoholik dengan perbandingan antara $\mathrm{NaOH}$ dan alkohol sebanyak 2:1. Larutan $\mathrm{NaOH}$ alkoholik berfungsi sebagai media reaksi untuk pelarutan gondorukem. Penambahan dilakukan sedikit demi sedikit agar reaksi berlangsung dengan sempurna. Suhu diturunkan menjadi $150^{\circ} \mathrm{C}$ dan dijaga hingga stabil.

Derajat keasaman $(\mathrm{pH})$ berdasarkan SNI nilai derajat keasaman darih rosin komersial adalah 9-10, nilai ini sesuai dengan hasil penelitian bahwa kontrol (tanpa perlakuan penambahan asam maleat) nilai derajat keasamannya adalah 9. Kemudian seiring ditambahkannya perlakuan asam maleat, nilai derajat keasamannya menurun seperti terlihat pada Gambar 5. Hal ini menunjukkan bahwa semakin banyak jumlah asam maleat anhidrida yang ditambahkan pada serbuk gondorukem akan terbentuk senyawa rosin maleat dengan $\mathrm{pH}$ yang semakin bersifat asam. Dilihat dari grafik diatas, penambahan maleat anhidrida sebanyak $3 \%$ sesuai dengan nilai $\mathrm{pH}$ rosin komersial yaitu 9,77 dengan sifat basa.

Proses saponifikasi gondorukem yang telah selesai akan digunakan dalam aplikasi pembuatan kertas. Pada aplikasi pembuatan kertas ini gel gondorukem yang telah terbentuk dilarutkan dalam air hingga larut dan dicampurkan dengan alum dalam jumlah tertentu. Larutan ini digunakan untuk penambahan pada stock yang akan dibuat menjadi sheet kertas dengan proses internal sizing. Tetapi didapatkan hasil bahwa rosin emusi yang terbentuk dilakukan pelarutan dalam air tidak dapat larut seperti yang terlihat pada Gambar 6. Rosin emulsi yang terbentuk pada proses saponifikasi tidak dapat larut dalam air. Hal ini dikarenakan perbandingan persentase penambahan $\mathrm{NaOH}$ terhadap persentase bahan baku gondorukem yang terlalu sedikit. Penambahan yang sedikit ini menyebabkan tidak semua asam lemak yang terdapat pada gondorukem tersaponifikasi secara sempurna menjadi bentuk sabun (rosin soap). Jenis asam

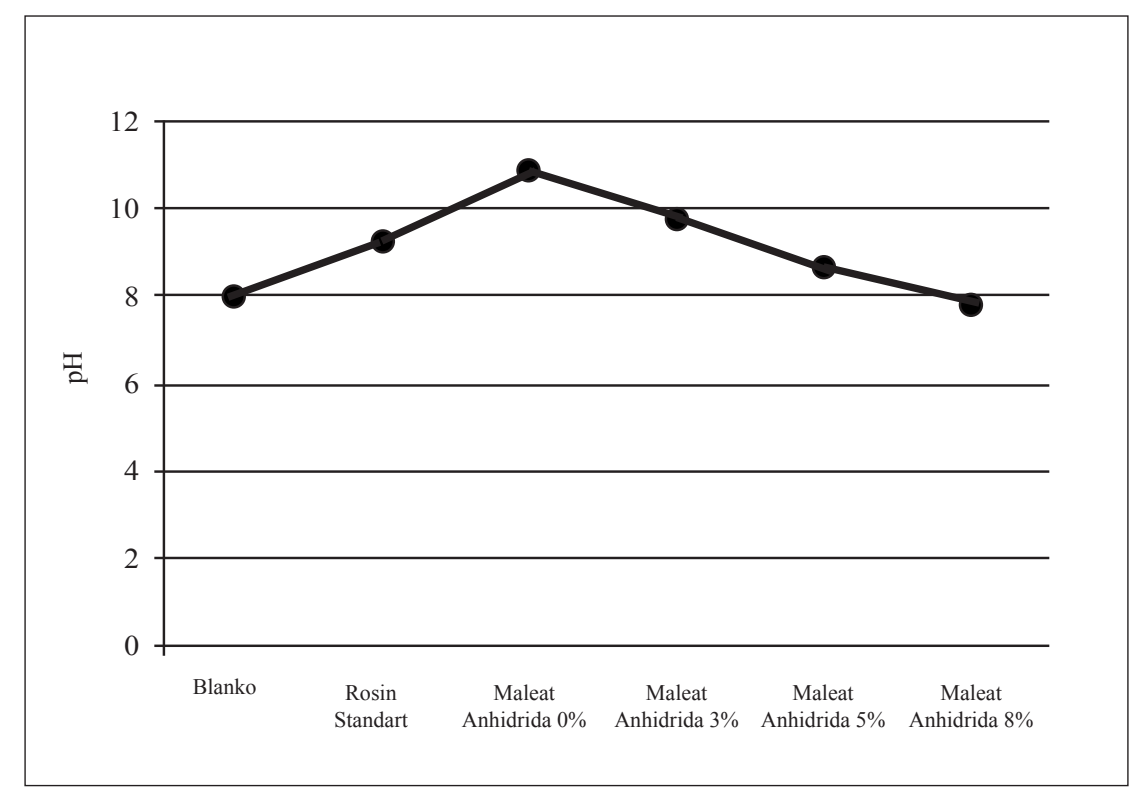

Gambar 5. Hasil Uji Derajat Keasaman (pH) Penambahan Maleat Anhidrida 
lemak yang terkandung dalam gondorukem yang merupakan jenis asam lemak rantai pendek menyebabkan banyak reaksi samping yang terbentuk (Wiyono dan Tachibana, 2008). Sehingga rendemen yang dihasilkan berupa rosin soap cenderung kecil.

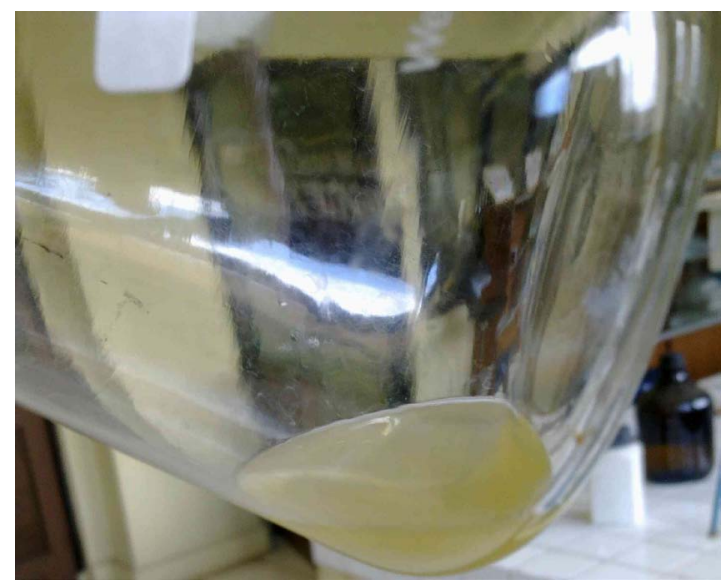

Gambar 6. Uji Kelarutan dari Rosin Emulsi dalam Air yang Tidak Larut.

\section{KESIMPULAN}

Gondorukem kualitas $\mathrm{X}$ lebih sesuai digunakan untuk pembuatan aditif rosin size dibandingkan gondorukem kualitas WW. Gondorukem kualitas X memenuhi spesifikasi bahan baku untuk pembuatan rosin size yaitu warna kuning jernih yang menandakan tidak mudah untuk teroksidasi. Bilangan asam gondorukem kualitas $\mathrm{X}$ adalah 179,92 yang menandakan bahwa kandungan asam lemaknya lebih tinggi daripada kualitas WW yaitu 176,58. Bilangan penyabunan gondorukem kualitas $\mathrm{X}$ yaitu 199,74 lebih tinggi daripada kualitas WW $(195,84)$ sehingga memerlukan basa yang lebih banyak untuk pembuatan rosin saponifikasi. Rosin saponifikasi yang dihasilkan belum dapat larut dalam air dikarenakan masih banyaknya campuran asam lemak yang tidak seluruhnya diubah ke dalam bentuk garamnya sehingga masih perlu dicari variasi penambahan yang lain agar rosin saponifikasi dapat larut.

\section{SARAN}

Penelitian agar dilanjutkan pada tahapan selanjutnya yaitu mencari kondisi optimum pembuatan rosin fortifikasi dengan penambahan asam anhidrida maleat. Penelitian aplikasi perlu dilakukan pada pembuatan kertas agar diketahui perbedaan antara rosin yang dibuat dengan rosin komersial digunakan pada pembuatan kertas.

\section{UCAPAN TERIMA KASIH}

Kami mengucapkan terima kasih kepada semua pihak yang telah membantu dalam proses berlangsungnya penelitian ini yaitu teknisi dari laboratorium kimia fisika Ibu Srihartini, teknisi dari laboratorium stock preparation $\mathrm{Ibu} \mathrm{Cucu}$ dan Pak Endang serta pihak lain yang tidak dapat disebutkan satu per satu.

\section{DAFTAR PUSTAKA}

Boer E., Ella, A, B. 2001. Plant Resources of South-East Asia No. 18. Plants Producing Exudates. Bogor: Prosea

Casey, J.P. 1981. Pulp and Paper Chemistry and Chemical Technology. Vol 3. New York: Intersciene Publiser.

Coppen, J. J. W., Hone, G. A. 1995. Non Wood Forest Product 2. http://www.fao.org. Diakses pada 15 Agustus 2013

Djatmiko, B., Sumadiwangsa, S., Ketaren, S., 1973. Pengujian Kualitas Gondorukem. Publikasi Khusus, 10:4-19.

Haris, G. E., 1953. Rosin and Rosin Derivatives. Encyclopedia of Chemical Technology. Volume ke-11. New York: The Intersciene Encyclopedia, Inc.

Indriati, L., Hidayat, T., 1993. Pendarihan Dengan Rosin Emulsi. Berita Selulosa Vol. XXIX No.3. Bandung: Balai Besar Selulosa.

Kirk, R.E., Othmer, D. F., . 1972. Rosin and Rosin Derivatives. Encyclopedia of Chemical Technology. Volume ke-17. New York: The Intersciene Encyclopedia, Inc.

Fachrodji, A., 2010, "Model Daya Saing Produk Gondorukem di Pasar Internasional dan Implikasinya terhadap Pengembangan Industri Gondorukem di Indonesia", Tesis. Fakultas kehutanan. Institut Pertanian Bogor.

Siregar, M. R. U. 2002. "Pengaruh Penambahan Asam Maleat dan Asam Fumarat Terhadap Rendemen dan Kualitas Gondorukem Modifikasi”, Skripsi. Fakultas Kehutanan. Intitut Pertanian Bogor

Standar Nasional Indonesia. 2001. Gondorukem Indonesia. SNI 01.5009.12-2001. Jakarta: Badan Standarisasi Nasional. 
Standar Nasional Indonesia. 1999. Darih Rosin Tersabunkan Penuh (Pasta Rosin Size). SNI 14.1118.1999. Jakarta: Badan Standarisasi Nasional.

Summers, H. B., Hendrick, G. W., 1962. Paper Size from Pine Oleoresin. Florida: US Departement of Agriculture, Olustee.

Technical Association of Pulp and Paper Industry Standard. 2001. Analysis of Rosin Size. T628 cm-01. United State: Tag and Label manufacturers Institute, Inc.
Wiyono, B., Tachibana, S., 2008. Maleo-and fumaro-pimaric acids Synthesized from Indonesian Pinus merkusii rosin and their sizing properties. Pak.J.Biol.Sci. In Press.

Wiyono, B., 2009. Chemical Treatment on Indonesian Pine Oleoresin and Rosin in Making Fortified Rosin used for Sizing Agent in Paper Making Process. Ehime University, Japan, in press. 